\title{
METODE PEMBIASAAN BIMBINGAN KEAGAMAAN \\ DALAM MEMBENTUK AKHLAKUL KARIMAH SANTRI DINIYAH TAKMILIYAH AWALIYAH AL ISTIQOMAH
}

\author{
Hermansyah, Siti Julaeha \\ Bimbingan Penyuluhan Islam STID Sirnarasa \\ herman_grt86@yahoo.co.id
}

\begin{abstract}
ABSTRAK
Akhlak menempati posisi yang sangat penting dalam Islam, oleh karena itu, seorang muslim berkewajiban memiliki akhlak sesuai dengan ajaran Islam. Hal ini sudah dicontohkan oleh Baginda Nabi Muhammad SAW yang merupakan suri tauladan untuk seluruh umat manusia. Penelitian ini bertujuan untuk mengetahui gambaran secara jelas bagaimana bimbingan keagamaan, materi bimbingan keagamaan, faktor pendorong dan penghambatnya, serta profil akhlak santri di DTA AlIstiqomah. Adapun jenis penelitian ini adalah penelitian kualitatif dengan menggunakan tehnik pengumpulan data, berupa angket, wawancara dan dokumentasi sehingga informasi yang diterima benar-benar obyektif. Sementara dalam proses analisa datanya menggunakan analisa data kualitatif dan kuantitatif melalui reduksi data, penyajian data dan verifikasi data. Hasil penelitian ini, menunjukkan bahwa akhlak santri diniyah termasuk kategori tinggi. Dalam penelitian ini, terungkap bahwa lembaga DTA Al-Istiqomah sudah dapat memfasilitasi anak didik dengan materi dan sarana belajar yang proporsional bagi anak didik. Sebagai lembaga DTA Al-Istiqomah yang berlabelkan pendidikan Islami, lembaga ini berusaha untuk menampilkan guru pembimbing sebagai figur sentral untuk dicontoh. Berdasarkan hasil penelitian maka metode yang digunakan di DTA Al Istiqomah dalam proses belajar telah sesuai dan perlu ditingkatkan dalam rangka membentuk akhlakul karimah santri diniyah (DTA) Al Istiqomah sehingga menjadi teladan yang mampu menanamkan nilai-nilai ke Islaman.
\end{abstract}

Kata Kunci : Bimbingan Keagamaan, Akhlak Santri Diniyah

\section{ABSTRACT}

Morals occupy a very important position in Islam, therefore, a Muslim is obliged to have morals in accordance with Islamic teachings. This has been exemplified by the Prophet Muhammad SAW who is a role model for all mankind. This study aims to determine a clear picture of how religious guidance, religious guidance material, driving and inhibiting factors, and the moral profile of students in the Al-Istiqomah DTA. This type of research is qualitative research using data collection techniques, in the form of questionnaires, interviews and documentation so that the information received is truly objective. Meanwhile, the data analysis process uses qualitative and quantitative data analysis through data reduction, data presentation and data verification.The results of this study indicate that the morals of the santri diniyah are in the high category. In this study, it was revealed that the Al-Istiqomah DTA institution was able to facilitate students with proportional learning materials and facilities for students. As an Al-Istiqomah DTA institution labeled Islamic education, this institution strives to present a supervisor as a central figure to be emulated. Based 
on the results of the research, the method used in the Al Istiqomah DTA in the learning process is appropriate and needs to be improved in order to form the morals of Al Istiqomah santri (DTA) so that it becomes a role model capable of instilling Islamic values.

Keywords: Religious Guidance, Santri Diniyah Morals

\section{PENDAHULUAN}

Santri Diniyah Takmiliyah Awaliyah (DTA) adalah santri yang belajar di Diniyah Takmiliyah Awaliyah. Sebagian besar santri Diniyah Takmiliyah Awaliyah adalah usia sekolah dasar yang sifat kekanak-kanakannya masih melekat pada diri mereka sehingga belum bisa menempatkan mana yang boleh dikerjakan dan mana yang tidak boleh dikerjakan. Maka melihat permasalahan ini,

Diniyah Takmiliyah Awaliyah (DTA) Al Istiqomah yang berada di Dusun Ciomas Desa Ciomas Kecamatan Panjalu Kabupaten Ciamis, memberikan pengajaran akhlak dengan menerapkan pembiasaan akhlak yang baik agar sifat kekanak-kanakan mereka dapat berubah menjadi lebih dewasa sehingga mengetahui mana yang boleh dikerjakan dan mana yang harus ditinggalkan sesuai dengan tuntunan yang disyariatkan dalam ajaran Agama Islam, sehingga dapat biasa dilakukan dalam kehidupan sehari-hari.

Pada zaman era globalisasi dan modernisasi seperti sekarang ini, krisis akhlak remaja sudah sangat merajalela dan semakin mengkhawatirkan. Maraknya kenakalan remaja, mengikuti tren gaya hidup orang barat, orientasi untuk hidup berfoya-foya, di keluarga tidak patuh terhadap orang tua, tidak sopan dengan orang lain, memuaskan diri-sendiri, dan memenuhi hawa nafsu adalah salah satu contoh jauhnya akhlak mereka dari akhlak yang baik dan luhur yang disyariatkan oleh agama Islam.

Untuk mengantisipasi kasus yang terjadi seperti di atas, maka perlu didirikan sebuah lembaga yang disebut madrasah, supaya akhlak remaja dapat dibentuk menjadi akhlak yang sesuai dengan syariat Islam melalui bimbingan keagamaan yang diajarkan oleh guru/ustadz di Diniyah Takmiliyah Awaliyah Al-Istiqomah Dusun Ciomas Desa Ciomas Kecamatan Panjalu Kabupaten Ciamis.

Dari pemaparan di atas, maka yang peneliti maksud dengan judul tersebut adalah metode pembiasaan bimbingan keagamaan yang dilakukan oleh seorang guru/ustadz kepada santri madrasah diniyah agar santri dapat mengembangkan potensi yang dimiliki dan mampu mengatasi kesulitannya sendiri, sehingga menjadi pribadi yang tangguh, bertanggung jawab, dan bermanfaat untuk keluarga dan masyarakat. Berdasarkan penjelasan diatas, maka peneliti tertarik untuk meneliti tentang Metode Pembiasaan Bimbingan Keagamaan dalam Membentuk Akhlakul Karimah Santri Diniyah Takmiliyah Awaliyah Al Istiqomah.

\section{LANDASAN TEORI}

\section{Pengertian Metode Pembiasaan}

Metode lazim diartiakan sebagai cara untuk mendekati masalah sehingga diperoleh hasil yang memuaskan. Contohnya dalam pembelajaran di sekolah, guru senantiasa memberikan contoh metode pembiasaan ini agar siswa dapat memahami semua aspek materi pelajaran dengan baik yang sesuai dengan tujuan pendidikan maka, dengan hal tersebut setiap guru harus mampu menggunakan metode ini demi tercapainya tujuan yang diinginkan.

Secara etimologi metode berasal dari bahasa yunani yang terdiri dari penggalan kata "meta" yang berati: melalui dan "hodos" yang berarti "jalan". Bila digabungkan maka metode bisa diartikan "jalan yang harus dilalui". Dalam pengertian yang lebih luas, metode bisa pula diartikan 
sebagai "segala sesuatu atau cara yang digunakan untuk mencapai tujuan-tujuan yang diinginkan". Dalam Kamus Besar Bahasa Indonesia, metode adalah cara teratur yang digunakan untuk melaksanakan suatu pekerjaan agar tercapai sesuai dengan apa yang dikehendaki. Dan juga merupakan cara kerja yang konsisten untuk memudahkan pelaksanaan suatu kegiatan guna mencapai tujuan yang direncanakan.

Dari pengertian diatas dapat ambil kesimpulan bahwa metode merupakan suatu jalan, cara atau tehnik yang baik dalam suatu kegiatan atau pekerjaan untuk mencapai tujuan yang dikehendaki atau direncanakan untuk mencapai tujuan yang diinginkan.

Pembiasaan merupakan salah satu metode pendidikan yang sangat penting, terutama bagi anak-anak. Mereka belum menyadari apa yang disebut baik dan buruk dalam arti susila. Mereka juga belum mempunyai kewajiban-kewajiban yang harus dikerjakan seperti pada orang dewasa, sehingga mereka perlu dibiasakan dengan tingkah laku, keterampilan, kecakapan, dan pola pikir tertentu yang baik.

Dalam menanamkan pembiasaan yang baik, Islam mempunyai berbagai cara dan langkah, yaitu : Islam menggunakan gerak hati yang hidup dan intuitif, yang secara tiba-tiba membawa perasaan dari suatu situasi ke situasi yang lain. Lalu Islam tidak membiarkannya menjadi dingin, tetapi langsung mengubahnya menjadi kebiasaan-kebiasaan yang berkait-kait dengan waktu, tempat, dan orang-orang lain. Demi tercapainya tujuan pembiasaan yang sesuai dengan nilai dan norma yang berlaku dalam kehidupan beragama maka, langkah pembiasaan tersebut harus didasari dengan hati nurani yang luhur.

Faktor terpenting dalam pembentukan kebiasaan adalah pengulangan, sebagai contoh seorang anak melihat sesuatu yang terjadi di hadapannya, maka ia akan meniru dan kemudian mengulang-ulang kebiasaan tersebut yang pada akhirnya akan menjadi kebiasan. Melihat hal tersebut, faktor pembiasaan memegang peranan penting dalam mengarahkan pertumbuhan dan perkembangan anak untuk menanamkan agama yang lurus. ${ }^{1}$ Hal yang terpenting adalah memberikan contoh yang positif sehingga seorang anak akan melakukan kebiasaan tersebut secara berulang-ulang.

\section{Pengertian Bimbingan Dan Keagamaan}

Menurut Shertzer \& Stone, Istilah bimbingan berasal dari kata guidance dengan kata dasar guide yang berarti menunjukkan, menentukan, mengatur atau mengemudikan. Selanjutnya kata ini memiliki pengertian yang berbeda-beda, diantaranya menurut Kartadinata, menjelaskan bahwa bimbingan merupakan proses membantu individu untuk mencapai perkembangan optimal. Menurut Shertzer \& Stone, bahwa bimbingan adalah proses membantu individu untuk memahami dirinya membantu mengetahui dan dunianya. Menurut mortensen \& Schmuller, bimbingan didefinisikan sebagai bagian dari total program pendidikan yang membantu menyediakan peluang pribadi dan layanan staf khusus dimana setiap individu dapat mengembangkan sepenuhnya kemampuan dan kapasitasnya dalam hal ide demokratis.

Dari pengertian diatas dapat dijelaskan bahwa, bimbingan merupakan proses bantuan kepada individu (konseli) sebagai bagian dari program pendidikan yang dilakukan yang dilakukan oleh tenaga ahli (konselor) agar individu (konseli) mampu memahami dan mengembangkan potensinya secara optimal sesuai dengan tuntutan lingkungannya.

Armai Arief, Pengantar Ilmu dan Metodologi Pendidikan Islam (Jakarta: Ciputat Press 2002), hlm. 665. 
Sedangkan Agama adalah ciptaan Allah, maka alangkah baiknya bagi akal sehat, hamba Allah yang diperintahkan untuk melaksanakan sesuatu hal yang di Ridhoi Allah SWT. Setiap pribadi orang muslim beramal untuk akhirat atas petunjuk dan ilham. Keagamaan yang benar yang tumbuh dan dikembangkan dari ajaran-ajaran islam yang bersih dan suci.

Menurut Aunur Rahim Faqih dalam buku "Bimbingan dan Konseling dalam Islam" Bimbingan keagamaan adalah proses pemberian bantuan terhadap individu agar dalam kehidupan keagamaannya senantiasa selaras dengan ketentuan dan petunjuk Allah, sehingga dapat mencapai kebahagiaan hidup di dunia dan akhirat. ${ }^{2}$ Dapat dipahami, bahwa bimbingan keagamaan itu merupakan proses bantuan yang dilakukan oleh seseorang ahli (disebut konselor) kepada individu yang mempunyai ajaran-ajaran Islam yang bersih dan suci (muslim) dengan salah satu tehnik dalam pelayanan bimbingan, dimana proses pemberian bantuan itu berlangsung melalui wawancara dalam serangkaian pertemuan langsung dan tatap muka antara konselor dan seorang muslim. Agar mampu hidup selaras dengan ketentuan dan petunjuk Allah SWT. Sehingga dapat mencapai kebahagiaan hidup di dunia dan di akhirat.

\section{Akhlak}

\section{Pengertian Akhlak}

Secara bahasa kata akhlak berasal dari bahasa Arab Al-akhlak, yang merupakan bentuk jamak dari kata khuluq atau al-khaliq yang berarti : Tabiat, budi pekerti; Kebiasaan atau adat; Keperwiraan, kesatriaan, kejantanan. Sedangkan pengertian secara istilah, akhlak adalah suatu keadaan yang melekat pada jiwa manusia, yang melahirkan perbuatan-perbuatan yang mudah, tanpa melalui proses pemikiran, pertimbangan atau penelitian.

\section{Tujuan Akhlak}

Islam mengatur kehidupan menusia seimbang antara dunia dan akhirat. Islam memberi kebebasan manusia untuk memperoleh kebahagiaan dunia dan akhirat. Ali Hasan mengatakan: tujuan akhlak adalah " agar setiap orang berbudi pekerti (berakhlak), bertingkah laku (bertabiat), berperangai atau beradat istiadat yang baik, yang sesuai dengan ajaran Islam”. Dari uraian diatas dapat diambil kesimpulan, bahwa tujuan pokok dari pendidikan akhlak adalah agar manusia dapat mengerti dan memahami tentang baik buruknya tingkah laku, sehingga manusia bisa memilih mana yang baik dan mana yang buruk yang sesuai dengan ajaran agama islam yang berpegang teguh pada dasar hukum agama Islam yaitu Al-Quran dan hadits, sebagaimana yang dicontohkan oleh Nabi Muhammad SAW yang merupakan uswatun hasanah bagi seluruh ummat manusia.

\section{Cara Meningkatkan Kualitas Akhlak}

Peningkatan kualitas akhlak penting dilakukan untuk mencapai kemuliaan hidup. Diantara cara atau metode dalam usaha meningkatkan kualitas akhlak adalah: Melalui perumpamaan (tamtsil); keteladanan (uswatun hasanah); Melalui latihan dan pengalaman; Melalui Ibrah dan Mau'izah ${ }^{3}$

\section{Faktor-faktor yang Mempengaruhi Pembentukan Akhlak}

Untuk menjelaskan faktor-faktor yang mempengaruhi pembentukan akhlak pada khususnya dan pendidikan pada umumnya, ada tiga aliran yang sudah amat populer. Pertama aliran Nativisme. Kedua aliran Empirisme. dan Ketiga aliran Konvergensi.

\footnotetext{
${ }^{2}$ Aunur Rahim Faqih, Op, Cit, hlm. 62.

${ }^{3}$ Kementrian Agama Republik Indonesia, Op, Cit, hlm. 38.
} 
Dalam konsep behavioral, bahwa Perilaku seseorang merupakan hasil belajar, sehingga dapat diubah dengan memanipulasi dan mengkreasi kondisi-kondisi belajar. ${ }^{4} \mathrm{Jadi}$, dengan adanya belajar maka perilaku seseorang itu dapat berubah sesuai dengan yang diperoleh pada waktu belajarnya, dengan demikian seorang pembimbing ataupun guru sangat berpengaruh terhadap proses perubahan perilaku seseorang dengan dapat menggunakan berbagai cara dalam mengarahkan seseorang agar dia dapat memahami apa yang pembimbing atau guru sampaikan baik dengan metode pembiasaan, metode mau'idzah hasanah, metode ibrah, metode keteladanan dan lain-lain .

\section{Santri}

Santri adalah para peserta didik yang mendalami ilmu-ilmu agama di pesantren baik dia tinggal di pondok maupun pulang setelah selesai waktu belajar. Pengertian diatas yang dipakai dalam lingkungan orang-orang pesantren, seorang alim hanya bisa disebut kyai bilamana memiliki pesantren dan santri yang tinggal dalam pesantren untuk mempelajari kitab-kitab klasik. Oleh karena itu santri merupakan elemen penting dalam suatu lembaga pesantren.

Metode yang diterapkan dalam membentuk perilaku santri yaitu:

a. Metode keteladanan (uswah hasanah)

b. Metode latihan dan pembiasaan

c. Metode mengambil pelajaran (ibrah)

d. Metode nasehat (mau'idzah)

e. Metode kedisiplinan

f. Metode pujian dan hukuman

g. Metode melalui kemandirian

\section{METODE PENELITIAN}

Tujuan penelitian ini adalah memahami metode pembiasaan bimbingan keagamaan dalam membentuk akhlakul karimah santri Diniyah Takmiliyah Awaliyah (DTA) Al Istiqomah. Jenis penelitian yang digunakan dalam penelitian ini adalah penelitian kualitatif pendekatan kuantitatif, menurut Uhar Suharsaputra penelitian kualitatif adalah prosedur yang menghasilkan data deskriptif yang berupa kata-kata tertulis ataupun secara lisan dari orang-orang dan perilaku yang diamati. ${ }^{5}$

Pada pengambilan sampel penulis berpijak pada pendapat Suharsimi Arikunto yang mengatakan bahwa "apabila subjek kurang dari 100 orang, maka dapat diambil semuanya, tetapi apabila lebih dari 100 orang maka dapat diambil 10-25\% atau lebih". ${ }^{6}$ Berhubungan jumlah santri yang ada sebanyak 30 orang maka peneliti mengambil semuanya.

Tehnik yang dipilih dalam pengumpulan data, penulis menggunakan angket, observasi, wawancara dan dokumentasi.

\section{HASIL DAN PEMBAHASAN}

Deskripsi data yang akan disajikan dari hasil penyebaran angket tentang indikator akhlak santri diniyah takmiliyah awaliyah (DTA) Al Istiqomah ini adalah memberikan gambaran secara umum mengenai penyebaran data yang diperoleh dilapangan. Data yang disajikan berupa data mentah yang diolah menggunakan tehnik deskripsi.

\footnotetext{
${ }^{4}$ Mohamad Surya, Op, Cit, hlm. 25.

${ }^{5}$ Uhar Suharsaputra, metode penelitian kuantitatif dan kualitatif dan tindakan (Bandung: Refika Aditama, 2012), hlm. 181.

${ }^{6}$ Suharsimi Arikunto, Prosedur Penelitian Suatu Pendekatan Praktis (Jakatra: Rineka Cipta, 2001), hlm. 62.
} 
Berdasarkan data mentah untuk variabel akhlak santri dari hasil penyebaran angket pada 30 responden, dengan jumlah pertanyaan 30 item. Peneliti menyusun daftar pertanyaan dalam bentuk skala guttman yang terdiri dari ya dan tidak. Penilaian yang diberikan pada jawaban pertanyaan positif bila menjawab ya diberi nilai atau skor 1 dan untuk pertanyaan negatif bila menjawab tidak diberi nilai atau skor 1 . Untuk pertanyaan positif bila menjawab tidak diberi nilai atau skor 0 dan untuk pertanyaan negatif bila menjawab ya diberi skor atau nilai 0. Sebagaimana dapat dilihat di pada tabel berikut:

Tabel 4.6

Pedoman Penskoran instrumen Akhlak Santri

\begin{tabular}{|c|c|c|c|}
\hline NO & $+/-$ & Ya & Tidak \\
\hline 1 & + & 1 & 0 \\
\hline 2 & - & 0 & 1 \\
\hline
\end{tabular}

Dengan mengacu pada nilai setiap item, maka akan diperoleh skor Maksimal 30x1=30, dan skor Minimal 30x0=0.

1. Menentukan Mean dengan rumus berikut:

$$
\begin{aligned}
\text { M } & =\frac{\text { Skor Maksimal }+ \text { Skor Minimal }}{2} \\
& =\frac{30+0}{2} \\
& =15
\end{aligned}
$$

2. Menentukan Standar Deviasi dengan rumus berikut:

$$
\begin{aligned}
\text { SD } & =\frac{\text { Skor Maksimal }- \text { Skor Minimal }}{6} \\
& =\frac{30-0}{6} \\
& =5
\end{aligned}
$$

3. Mencari Kategorisasi dengan rumus berikut:

$$
\begin{gathered}
X<(\mu-1,0 \sigma) \quad \text { Rendah } \\
X<(15-1.0 \times 5) \\
X<(15-5) \\
X<10 \\
(\mu-1,0 \sigma) \quad X<(\mu+1,0 \sigma) \quad \text { Sedang } \\
(15-1,0 \times 5) \leq X<(15+1,0 \times 5) \\
(15-5) \leq X<(15+5) \\
(10) \leq X<(20) \\
(\mu+1,0 \sigma) \leq X
\end{gathered}
$$

\footnotetext{
${ }^{7}$ Saifuddin Azwar, Penyusunan Skala Psikologi Edisi Ke-2, Cet Ke- XIII (Yogyakarta: Pustaka Pelajar, 2018), hlm.
} 149. 
$(15+1,0 \times 5) \leq \mathrm{X}$

$(15+5) \leq \mathrm{X}$

$(20) \leq X$

Tabel 4. 7

Data Hasil Skor kategori Akhlak Santri Diniyah

\begin{tabular}{|c|c|c|c|}
\hline NO & Nama & Score & Kategori \\
\hline 1 & Ashty & 29 & Tinggi \\
\hline 2 & Fachri & 29 & Tinggi \\
\hline 3 & Khayla & 29 & Tinggi \\
\hline 4 & Nanda & 29 & Tinggi \\
\hline 5 & Riki & 29 & Tinggi \\
\hline 6 & Nurul & 29 & Tinggi \\
\hline 7 & Anisa & 28 & Tinggi \\
\hline 8 & Aldi & 28 & Tinggi \\
\hline 9 & Agis & 28 & Tinggi \\
\hline 10 & Ilham & 28 & Tinggi \\
\hline 11 & Karen & 28 & Tinggi \\
\hline 12 & Luthfi & 28 & Tinggi \\
\hline 13 & Nabil & 28 & Tinggi \\
\hline 14 & Melly & 28 & Tinggi \\
\hline 15 & Naufal & 28 & Tinggi \\
\hline 16 & Tria & 28 & Tinggi \\
\hline 17 & Adnan & 27 & Tinggi \\
\hline 18 & Aqilla & 27 & Tinggi \\
\hline 19 & Deria & 27 & Tinggi \\
\hline 20 & Mersi & 27 & Tinggi \\
\hline 21 & Hifdzi & 26 & Tinggi \\
\hline 22 & Latif & 26 & Tinggi \\
\hline 23 & Ani & 26 & Tinggi \\
\hline 24 & Sri & 26 & Tinggi \\
\hline 25 & Alia & 25 & Tinggi \\
\hline 26 & Akbar & 24 & Tinggi \\
\hline 27 & Heri & 24 & Tinggi \\
\hline 28 & Desi & 23 & Tinggi \\
\hline 29 & Rida & 23 & Tinggi \\
\hline 30 & Ghina & 20 & Tinggi \\
\hline
\end{tabular}

Dari hasil perhitungan data akhlak santri sebanyak 30 responden dapat ditetapkan bahwa kategorisasi semua responden dapat didiagnosis sebagai memiliki akhlak yang tinggi.

\section{KESIMPULAN}

Berdasarkan hasil penelitian yang dilakukan oleh penulis tentang metode pembiasaan bimbingan keagamaan dalam membentuk akhlakul karimah santri DTA Al Istiqomah maka dapat diambil kesimpulan sebagai berikut: 
1. Proses bimbingan keagamaan yang dilaksanakan di Diniyah Takmiliyah Awaliyah (DTA) Al Istiqomah yaitu menggunakan metode kelompok dan metode individu, dan kurikulum yang digunakan yaitu mengambil dari kementrian agama. Pembiasaan yang diterapkannya adalah membaca Al-Quran, hafalan surah pendek, hafalan doa-doa sehari-hari, berbicara baik, jujur, berperilaku sopan, membaca doa setiap mulai dan selesai melaksanakan kegiatan dan bersalaman ketika bertemu dengan ustadz / ustadzahnya.

2. Materi yang disampaikan di Diniyah Takmiliyah Awaliyah (DTA) Al Istiqomah diantaranya: bimbingan ibadah, baca tulis Al-Quran dan tajwid, aqidah, akhlak, sejarah kebudayaan Islam, bahasa arab.

3. Faktor pendorong dalam melaksanakan bimbingan keagamaam di DTA Al Istiqomah adalah tempat yang strategis jauh dari keramaian kota, gedung yang memadai permanen halaman luas, para ustadz dan ustadzahnya sudah banyak pengalaman.

4. Faktor penghambatnya adalah kurangnya dana, belum semua kualifikasi para ustadz/ustadzahnya.

5. Keberadaan akhlak santri DTA Al Istiqomah berdasarkan hasil penyebaran angket semua responden memiliki akhlak yang termasuk pada kategori tinggi.

Berdasarkan uraian penelitian diatas, maka penulis menyarankan:

1. Diharapkan para ustadz dan ustadzahnya untuk melanjutkan pendidikannya.

2. Kepada pemerintah mohon bantuannya memberikan sarana prasarana pendidikan berupa mebeler, sumber belajar dan fasilitas lainnya

3. Kepada para orang tua santri agar lebih memperhatikan biaya dalam pendidikan anaknya

4. Kepada para aghniya dan dermawan mohon bantuannya untuk membantu dalam proses bimbingan dan pembelajaran dengan memberikan bantuannya baik bidang moril maupun materil.

5. Kepada semua pihak dimohon untuk kerjasamanya agar bimbingan keagamaan berjalan lancar

6. Kepada para santri agar lebih meningkatkan kedisiplinannya dalam melaksanakan kegiatan bimbingan keagamaan terutama melaksanakan pembiasaan yang diterapkan di DTA.

\section{DAFTAR PUSTAKA}

Adi, Rianto, 2004, Metodologi Peneltian Sosial dan Hukum. (Jakarta: Granit).

Al- Ghazali, 1977, Ihya Ulumuddin, Jilid III (Dar-al-Mishri: Beirut).

Ali, Muhammad Daud, 2010, Pendidikan Agama Islam (Jakarta: PT. Raja Grafindo Persada).

Aminuddin, Dkk, 2002, Pendidikan Agama Islam Untuk Perguruan Tinggi (Jakarta: Ghalia Indonesia).

Amti, Erman dan H. Prayitno, 2008, Dasar-dasar Bimbingan dan Konseling (Jakarta: PT Rineka Cipta).

An-Nahlawi, Abd. Rahman, 1992, Prinsip-prinsip dan Metode Pendidikan Islam, diterjemahkan Dahlan dan Sulaiman, (Bandung: CV. Dipenogoro).

Arief, Armai, 2002, Pengantar Ilmu dan Metodologi Pendidikan Islam (Jakarta: Ciputat Press).

Azwar Saifuddin, 2018, Penyusunan Skala Psikologi Edisi Ke-2, Cet Ke- XIII (Yogyakarta: Pustaka Pelajar).

Buchari Alma, 2014, Pengantar Statistijka Sosial ( Bandung: Alfabeta).

Bungin Burhan, 2005, Metodoligi Penelitian Kuantitatif ( Jakarta: Kencana).

Burhanuddin, Tamyiz, 2001, Akhlak Pesantren: Solusi bagi kerusakan Akhlak (Yogyakarta: ITTIQA Press). 
Depag RI, 2002, Mushaf AL-Quran dan terjemahnya (Depok: Al-huda).

Departemen Pendidikan dan Kebudayaan, 1994, Kamus Besar Bahasa Indonesia, Cet. Ke-2, (Jakarta: Balai Pustaka). 